\title{
Correction to "Author's reply to Tovey and colleagues"
}

This Letter by Peter C Gøtzsche (BMJ 2015;350:h2955, doi:10. $1136 / \mathrm{bmj} . \mathrm{h} 2955)$, published in the print issue of 6 June 2015, has been edited for editorial and legal reasons.
Cite this as: BMJ 2015;350:h3138

๑ BMJ Publishing Group Ltd 2015 